\title{
Paisagem cultural e potencial paisagístico do Geopark
}

\author{
ÚRSULA RUCHKYS ${ }^{(1)}$ e MARIA MÁRCIA MAGELA MACHADO(1)
}

\begin{abstract}
RESUMO
Nas últimas décadas a associação de adjetivos à palavra patrimônio explicita a incorporação de novos conceitos ao sentido de bem, de algo de valor que deve ser preservado e transmitido de geração em geração. O que se observa é uma tendência recente de valorização da geodiversidade assim como já se fazia com a biodiversidade. Neste contexto, este artigo reporta como os conceitos de Geopark e Paisagem Cultural foram muito recentemente introduzidos no Brasil trazendo uma nova perspectiva para conservação e valorização dos patrimônios natural e cultural de forma integradora.
\end{abstract}

Palavras chave: patrimônio geológico, geoconservação, UNESCO.

\section{ABSTRACT}

Cultural landscape and scenic potencial of Geopark

In the last few decades several new senses were incorporated to heritage concept. What is observed is a recent trend of appreciation of geodiversity as well as occurred with biodiversity. In this context, this article reports how the concepts of Geopark and Cultural Landscape were recently introduced in Brazil, bringing a new perspective for conservation and appreciation of natural and cultural heritages in an integrative way.

Keywords: geological heritage, geoconservation, UNESCO.

\section{PATRIMÔNIO GEOLÓGICO E PAISAGEM CULTURAL}

A palavra patrimônio, de forma geral, está associada à herança, aquilo que é transmitido de geração para geração. Segundo CHOAY (2001) esta palavra foi requalificada por diversos adjetivos, como genético, natural, cultural, que fizeram dela um conceito nômade.

A Convenção de 1972 para Proteção do Patrimônio Mundial da UNESCO constitui um dos instrumentos mais importantes na conceituação e criação de um patrimônio de valor universal e considera, no Artigo 1 como patrimônio cultural: (1) os monumentos, incluindo obras de arquitetura, escultura, e pinturas além de estruturas de natureza arqueológica; (2) conjuntos de edificações que tenham valor universal por sua arquitetura, homogeneidade ou localização na paisagem; (3) sítios incluindo obras feitas pelo homem ou pela natureza e pelo homem em conjunto, incluindo sítios arqueológicos. No Artigo 2 da mesma Convenção, a UNESCO considera como patrimônio natural: (1) monumentos naturais constituídos por formações físicas e biológicas ou por um conjunto de formações; (2) formações geológicas e fisiográficas e as zonas estritamente delimitadas que constituam habitat de espécies animais e vegetais ameaçadas; (3) sítios naturais ou áreas naturais estritamente delimitadas detentoras de uma valor excepcional do ponto de vista da ciência, da conservação ou da beleza natural. No conceito de patrimônio natural da UNESCO aparece sob a designação de formações geológicas o patrimônio geológico. No entanto, definições e reflexões mais específicas sobre a natureza deste tipo de patrimônio são fornecidas por RIVAS et al. (2001) que define patrimônio geológico como os recursos naturais não renováveis de valor científico, cultural, educativo e/ou de interesse paisagístico e recreativo, que sejam formações rochosas, estruturas, geoformas, acumulações sedimentares ocorrências minerais, paleontológicas e outras que permitam reconhecer, estudar e interpretar a evolução da história geológica da Terra e os processos que a tem modelado. Desta forma, o patrimônio geológico, representado pelos sítios geológicos, pode ser definido como recurso documental de caráter científico, de conteúdo importante para o conhecimento e estudo da evolução dos processos geológicos e que constitui o registro da totalidade da evolução do planeta (RUCHKYS, 2007). Uma caracterização mais específica sobre a natureza do patrimônio geológico é importante embora a Convenção de 1972 reúna as noções de cultura e natureza (incluindo a geologia) no conceito de patrimônio.

A UNESCO estabelece que o reconhecimento em nível internacional do patrimônio deva ser feito segundo critérios que envolvem os seguintes valores: (1) estético: paisagens notáveis e de excepcional beleza e condição de paisagem de exceção;

(1)Universidade Federal de Minas Gerais - Instituto de Geociências - Departamento de Cartografia. Av. Antônio Carlos, 6677, Pampulha, Belo Horizonte-MG, CEP31270-901 e-mails: tularuchkys@yahoo.com.bre mmmachado@uol.com.br. 
(2) ecológico: sítios correspondendo a habitat de espécies em risco ou que detenham processos ecológicos e biologicamente importantes; (3) científico: áreas que contenham formações ou fenômenos relevantes para o conhecimento científico da história natural do planeta; (4) integridade dos bens (SCIFONI, 2003).

Os critérios estabelecidos pela UNESCO para o reconhecimento de patrimônios de valor universal deixam uma lacuna relacionada a paisagens de importância em escalas mais reduzidas, nos âmbitos nacional, regional e local. Para MANSUR et al. (2008) esta lacuna foi preenchida com o que se convencionou chamar de paisagem cultural, um conceito de uso relativamente novo no Brasil introduzido de forma pioneira durante Seminário "Semana do Patrimônio - Cultura e Memória na Fronteira" realizado em agosto de 2007 na cidade de Bagé, RS. Segundo IPHAN (2007), neste seminário decidiu-se pela elaboração de uma Carta à qual se conferiu o nome da cidade gaúcha onde se realizou o vanguardista encontro. Esta Carta, denominada Carta de Bagé ou Carta da Paisagem Cultural define, em seu Artigo 2, o termo paisagem cultural como sendo o meio natural ao qual o ser humano imprimiu as marcas de suas ações e formas de expressão, resultando em uma soma de todos os testemunhos da interação do homem com a natureza e, reciprocamente, da natureza com homem, passíveis de leituras espaciais e temporais. O IPHAN na portaria número 127, de 30 de abril de 2009 publicada no Diário Oficial da União estabelece a chancela da Paisagem Cultural Brasileira definindo em seu Art. $1^{\circ}$. A paisagem cultural brasileira como uma porção peculiar do território nacional, representativa do processo de interação do homem com o meio natural, à qual a vida e a ciência humana imprimiram marcas ou atribuíram valores.

Assim, o termo paisagem cultural deve ser usado para designar porções do território que contém, simultaneamente, elementos naturais e culturais. Algumas destas paisagens podem ser consideradas patrimônio devido a seu valor científico, estético, histórico, cultural, etc. Para DELPHIM (2009) paisagens com valores culturais e de importância científica, que apresentem elementos geológicos, geomorfológicos, estratigráficos, paleontológicos e outros, podem ser propostas para receber a chancela da Paisagem Cultural Brasileira. A chancela de Paisagem Cultural associada a outros instrumentos, em especial o Programa Geoparks da UNESCO, apresentado a seguir, veio somar forças no sentido de valorizar e reconhecer o patrimônio geológico como forma integrante da paisagem e de nosso patrimônio natural.

\section{PROGRAMA GEOPARKS DA UNESCO}

Para reforçar os projetos de conservação do patrimônio geológico (designada de geoconservação) em seu marco dos programas de Reservas da Biosfera e do Patrimônio Mundial, a UNESCO desenvolveu o Programa Geoparks a partir de várias fontes, principalmente européias. O Programa, que foi apresentado à comunidade científica em 1999, se destaca por atender a necessidade específica de reconhecimento e conservação do patrimônio geológico, da mesma forma como o Programa Reserva da Biosfera se destaca por sua ênfase no patrimônio biológico.

Segundo a UNESCO, um geopark é um território com limites bem definidos que abriga vários sítios geológicos ou geosítios, locais que são verdadeiros patrimônios cuja importância científica está no fato de serem registros singulares dos eventos ou processos evolutivos da área, permitindo, portanto, a compreensão da história geológica da Terra. Além disso, um "geopark" deve ter como atrativos valores paisagísticos, históricos e culturais que incentivem o geoturismo e, conseqüentemente, o desenvolvimento sustentável da região. A idéia é aliar conservação do patrimônio geológico, educação ambiental e geoturismo em favor da economia local sem criar qualquer restrição ao desenvolvimento das mais diversas atividades econômicas dentro dos limites do "geopark", inclusive daquelas que têm como matéria-prima recursos minerais. Isto é possível porque o princípio da geoconservação é pontual, apenas dos geosítios e não da área como um todo.

A proposta conciliadora deste Programa foi ganhando adeptos e importantes iniciativas em prol da geoconservação foram se sucedendo. Em 2000, ocorreu o Primeiro Simpósio Internacional de Proteção do Patrimônio Geológico e com ele a Declaração de Direito da Memória da Terra e a fundação da Rede Européia de Geoparks. No ano seguinte foi firmado o acordo de cooperação entre esta Rede e a Divisão de Ciências da Terra da UNESCO e, finalmente, em 2004, depois da formação da Rede Global de Geoparks Nacionais assistida pela UNESCO, a criação de "geoparks" passou a ser uma estratégia de geoconservação amplamente adotada, especialmente na Europa e na Ásia. Em 2004 mesmo foi criado um "geopark" na Áustria, um na França, 2 na Alemanha, e o incrível número de 7 na China. Hoje este país abriga 17 dos 45 "geoparks" reconhecidos pela UNESCO ao redor do mundo.

No Brasil, o Programa Geoparks começou a ser incorporado em 2006 com a criação do "geopark" Araripe, no Estado do Ceará. Outras iniciativas estão em andamento: Geopark Bodoquena no Mato Grosso do Sul, Geopark Campos Gerais no Paraná e o Geopark Quadrilátero Ferrífero na região centro-sudeste de Minas Gerais.

\section{O EXEMPLO DO QUADRILÁTERO FERRÍFERO}

No Brasil, um território privilegiado para uma ação baseada na proteção integrada do patrimônio, com a criação de um "geopark" é o Quadrilátero Ferrífero, em Minas Gerais. O QF ocupa uma área aproximada de $7.000 \mathrm{~km}^{2}$ na porção centro-sudeste do estado e é internacionalmente reconhecido como um importante terreno pré-cambriano com significativos recursos minerais, em especial ouro e ferro. O Quadrilátero Ferrífero reúne um conjunto de ocorrências geológicas que, pela sua singularidade, pode constituir a base para a criação de um "geopark" de relevância nacional e internacional, conforme proposto por Ruchkys (2007). As rochas que nele afloram datam do Arqueano e Paleoproterozóico, que juntamente com o Hadeano (Eon que marca os primórdios de formação do planeta), ocupam cerca de 8/10 da história 
de evolução da Terra. Os controles primários na evolução geológica da Terra Pré-Cambriana foram determinados pela interação entre a tectônica de placas, superplumas mantélicas, química do sistema oceano-atmosfera, evolução da vida e pelos processos de sedimentação. Encontram-se no Quadrilátero Ferrífero elementos geológicos representativos de parte da evolução Pré-Cambriana. Este registro está preservado nos seus diferentes conjuntos de rochas, que contam sua história geológica a qual inclui diversos eventos, como magmatismo e tectonismo e mudanças na atmosfera, hidrosfera, biosfera e nos sistemas de sedimentação.

Boa parte destes sítios geológicos presentes na região poderia também se enquadrar no conceito de Paisagem Cultural por integrarem valores culturais e naturais, um destaque especial é merecido para as referências geográficas e paisagísticas que podem ser observados de diferentes pontos do QF: Serra da Piedade, Serra do Curral, Pico de Itabira, Serra do Caraça. Pico do Itacolomi e Serra de Ouro Branco. Estes sítios sintetizam a relação entre as pessoas e as rochas - chamadas popularmente de pedras. Esta relação é muito bem sintetizada por Chagas e Chagas (2004) ao discorrerem sobre o patrimônio geológico do Rio de Janeiro: “As pedras também são baús, ou arcas que guardam memórias. A memória do mundo, de algum modo, está presente nas pedras. Não estamos falando aqui da memória da natureza, mas da memória cultural do mundo; não estamos considerando as pedras como entes naturais, mas como entes do universo cultural. Na relação com as pedras não encontramos apenas pinturas, escrituras, esculturas e templos, encontramos também faíscas do imaginário e da memória social. Pensemos no Pão de Açúcar, no Corcovado, na Pedra da Gávea, na Pedra Branca, no Morro da Urca, no Pico do Papagaio, no Pico da Tijuca e no Morro dos Dois Irmãos, por exemplo."

No Quadrilátero Ferrífero os sítios da Serra da Piedade, Serra do Curral, Pico do Itacolomi, Pico de Itabirito e Serra de Ouro Branco são alguns dos exemplos de como as pedras acompanham e fazem parte da própria história do lugar. Desde o final do século XVII estas pedras que se destacavam na paisagem serviam como referências geográficas para o deslocamento dos bandeirantes e depois dos tropeiros, caixeiros viajantes, mercadores de gado e, finalmente, para os viajantes naturalistas que se aventuravam pelas Minas Gerais durante o período do ciclo do ouro.

\section{PAISAGEM CULTURAL E GEOPARKS}

A base dos conceitos de "geopark" e de paisagem cultural envolve a relação do homem, das comunidades com sua paisagem, no caso específico dos "geopark"s com sua paisagem geológica, que faz parte do próprio desenvolvimento cultural do território e consequentemente de sua identidade.

Um "geopark" integra um território delimitado pelos sítios geológicos de interesse regional, sendo que vários destes sítios podem ser enquadrados no conceito de Paisagem Cultural. O "geopark" integra e dá significado ao conjunto de sítios geológicos de importância científica especial, beleza ou raridade e sua gestão deve ser determinada pela necessidade de conservar, valorizar e popularizar os testemunhos geológicos ali existentes, representativos da história geológica.

Neste contexto, a chancela de Paisagem Cultural que convive com as transformações inerentes ao desenvolvimento econômico e social sustentável constitui-se um instrumento importante de geoconservação dentro de uma região designada como "geopark". Conforme salientado por Delphim (2009), a declaração como Paisagem Cultural Brasileira propõe o estabelecimento de um pacto no qual cada órgão público cumpriria, de maneira exemplar, sua responsabilidade com cada um dos aspectos que caracterizam cada paisagem.

\section{CONSIDERAÇÕES FINAIS}

No conceito de "geoparks" da UNESCO alguns objetivos fundamentais do estabelecimento destas áreas são: 1) proporcionar o desenvolvimento ambientalmente e culturalmente sustentável, promovendo a identificação da comunidade local com sua área e estimulando novas fontes de receita, especialmente o geoturismo; 2) servir como uma ferramenta pedagógica para a educação ambiental, treinamento e pesquisa relacionada às disciplinas geocientíficas, proporcionando programas e instrumentos que aumentem a consciência pública sobre a importância do patrimônio geológico como museus geológicos e trilhas; 3) servir para explorar e demonstrar métodos de conservação do patrimônio geológico e deve contribuir para a conservação de aspectos geológicos significativos que proporcionem informações em várias disciplinas geocientíficas tais como Geologia Econômica, Física, Mineração, Estratigrafia, Mineralogia, etc.

Neste sentido, o "geopark" constitui-se como uma forma de salvaguardar o patrimônio geológico e, por outro lado, valorizá-lo para a comunidade local. Ao dar significado ao patrimônio geológico e integrar o território por meio deste significado, promove uma valorização do território e de sua paisagem.

Para RUCHKYS (2009), um dos principais objetivos dos "geoparks" é fazer com que sentimentos de proteção e valorização nasçam por meio da informação, da percepção e da emoção, numa releitura dos patrimônios. As pessoas somente se tornam educadas e comprometidas com o patrimônio que visitam, respeitando a cultura e os locais, quando, pelo conhecimento, percebem a importância do sítio visitado. É fundamental que sejam informadas sobre o local, suas características, fauna, flora, geografia, geologia, relações ecológicas, fatos relevantes de sua história, de sua cultura, da formação das sociedades, peculiaridades, enfim, tudo que possa ajudá-las a conhecerem e desvendarem o patrimônio. $\mathrm{O}$ conceito de "geopark"s e paisagem cultural têm muita coisa em comum e o reconhecimento de uma área como "geopark" ou de uma paisagem como Paisagem Cultural pode promover a valorização do território, alavancando o desenvolvimento territorial de maneira integrada com bases educativas. A memória, aqui valorizada e recuperada, diz respeito à história da evolução da Terra registrada nos fósseis, rochas, minerais, relevo e paisagens e sua relação com o próprio desenvolvimento cultural do território. 
Assim, ao promover a valorização do território, o "geopark" e a Paisagem Cultural desempenham um importante papel social, gerando a identificação do público com o patrimônio, estimulando sua conservação e divulgação de seu significado. No caso específico de áreas com grande valor patrimonial do ponto de vista da geologia e com conseqüente potencial de se enquadrarem no conceito de Geoparks, a chancela como Paisagem Cultural pode ser o primeiro passo para auxiliar na geoconservação.

\section{REFERÊNCIAS BIBLIOGRÁFICAS}

CHAGAS, M., CHAGAS, V. Memória Rupestre ou do Caminho no Meio da Pedra. Revista Museu, 2004. Disponível em: < http://www.revistamuseu.com.br/artigos/art_.asp?id=5295>. Acesso em: 07 abril 2010.

CHOAY, F. A Alegoria do Patrimônio. São Paulo: UNESP, 2001. Volume único, 282 p.

DELPHIM, C.F.M. Patrimônio Cultural e Geoparque. Geologia USP - Publicação Especial, São Paulo, v.5, p.75-83, 2009.

IPHAN (Instituto do Patrimônio Histórico e Artístico Nacional). Carta de Bagé. 2007. Disponível em <http: //portal.iphan.gov.br:8080/portal/ baixaFcdAnexo. do;jsessi onid=24E0F3F43EA29FDA472A61849CD67F19?id=895>. Acesso em: 05 abril 2010.
MANSUR, K.L., CARVALHO, I.S., DELPHIM, C.F.M., BARROSO, E.V. O Gnaisse Facoidal: a mais Carioca das Rochas. Anuário do Instituto de Geociências - UFRJ, Rio de Janeiro, v.31-32, p. 9-22, 2008.

RIVAS, F.V., RIVERA, F.M., GUADALUPE, G. Situación Ambiental del Patrimônio Geológico em El Perú. Revista Del Instituto de Investigación, v. 4, n. 8, p. 30-36, 2001. Disponível em: <http://www.scielo.org.pe/pdf/iigeo/v4n8/ a04v4n8.pdf>. Acesso em: 07 abril 2010.

RUCHKYS, U.A. Patrimônio Geológico e Geoconservação no Quadrilátero Ferrífero, Minas Gerais: Potencial para a Criação de um Geoparque da UNESCO. Belo Horizonte: Instituto de Geociências, UFMG, 2007. 211 p. Tese (Doutorado em Geologia).

RUCHKYS, U.A. Geoparques e a Musealização do Território: um Estudo sobre o Quadrilátero Ferrífero. Geologia USPPublicação Especial, São Paulo, v.5, p.35-46, 2009.

SCIFONI, S. Patrimônio Mundial: do Ideal Humanista à Utopia de uma Nova Civilização. Geousp - Espaço e Tempo, São Paulo, v.14, p.77-88, 2003.

UNESCO. Operational Guideline for National Geoparks Seeking UNESCO's Assistance, 2004. Disponível em: < http: //unesdoc.unesco.org/images/0015/001503/150332eo.pdf $>$. Acesso em: 07 abril 2010. 